\title{
PELAKSANAAN PELAYANAN TRANSPORTASI \\ SISTEM ANGKUTAN UMUM MASAL (SAUM) TRANS METRO KOTA PEKANBARU MENUJU ASIAN ECONOMIC COMMUNITY 2015
}

\author{
Muslim
}

(Dosen Fakultas Ekonomi dan Ilmu Sosial UIN Suska Riau)

\begin{abstract}
ABSTRAK
Kemajuan Kota Pekanbaru dari Kota menjadi Kota Besar dan sekarang berstatus Kota Metropolitan, tentu diikuti oleh perkembangan kota seperti pembangunan gedunggedung, perkantoran dan sarana publik lainnya. Salah satu sarana publik yang dikembangkan ialah Sistem Angkutan Umum Masal (SAUM) Trans Metro Kota Pekanbaru. Dalam pelaksanaan pelayanan publik Sistem Angkutan Umum Masal (SAUM) Trans Metro Kota Pekanbaru terdapat permasalahan sehingga belum dapat berperan penting dalam kehidupan dan pergerakan masyarakat dalam melakukan aktivitas terutama di kota bisnis ini dimana semua orang ingin melakukan sesuatu dengan cepat, tidak ada kata untuk menunggu. Tujuan dari penelitian ini ialah untuk mengetahui pelaksanaan pelayanan transportasi publik dan hambatan yang dihadapi. Penelitian ini melibatkan Dinas Perhubungan, Pengelola Trans Metro, dan masyarakat sebagai pengguna jasa. Hasil penelitian kualitatif ini menunjukan bahwa pelayanan trans metro Kota Pekanbaru belum maksimal dibuktikan dengan belum memiliki jalur khusus (separator) sehingga menimbulkan kemacetan dan seringnya kecelakanaan lalu lintas, shelter bus berada dimedian jalan, perilaku supir yang ugal-ugalan dengan kecepatan melewati ketentuan, jadwal waktu kedatangan dan keberangkatan bus yang tidak menentu sehingga menyebabkan enggannya masyarakat memilih transportasi ini.
\end{abstract}

Keyword : Pelayanan Publik, Trans Metro, Transportasi.

\section{PENDAHULUAN}

Kemajuan Kota Pekanbaru dari Kota menjadi Kota Besar dan sekarang berstatus Kota Metropolitan, tentu diikuti oleh perkembangan kota seperti pembangunan gedung-gedung, perkantoran dan sarana publik lainnya. Terutama menghadapi berbagai macam tantangan baik sipatnya lokal, regional maupun internasional. Salah satu tantangan ialah bergabungnya Indonesia sebagai salah satu negara yang ikut dalam Masyarakat Ekonomi Asian (Asean Economic Community) pada tahun 2015. Salah satu sarana publik yang mendapat 
perhatian khusus di berbagai kota besar dan atau metropolitan di Indonesia ialah sarana transportasi angkutan umum, disebabkan terjadinya permasalahan besar yang dihadapi ialah kemacetan, ketidakberatun di jalan raya sehingga berakibat kepada lambannya pergerakan atau mobilatas masyakat dalam melakukan berbagai aktifitas termasuk aktifitas ekonomi dan bisnis.

Pemerintah Kota Pekanbaru menyadari ancaman kemacetan kota tersebut sejak tahun 2007 dengan digagasnya usaha untuk mengendalikan kemacetan sekaligus meningkatkan kinerja pelayanan angkutan umum. Tujuannya untuk dapat menghasilkan sebuah kebijakan di bidang jasa transportasi yaitu peningkatan pelayanan pada angkutan umum massal yang aman, nyaman, dan ramah lingkungan. Pemerintah Kota Pekanbaru mengeluarkan kebijakan pelayanan transportasi perkotaan yang dikenal dengan Sistem Angkutan Umum Massal (SAUM) Trans Metro Pekanbaru, yang dilaksanakan berdasarkan Surat Keputusan Menteri Perhubungan Nomor 111 tahun 2009. Pada 18 Juni 2009 Pemerintah Kota Pekanbaru secara resmi meluncurkan Trans Metro Pekanbaru sebagai transportasi umum massal yang menggunakan bus sebagai transportasi pilihan bagi masyarakat.

Tabel 1.1 Tarif Trans Metro Pekanbaru

\begin{tabular}{|c|c|c|c|}
\hline Tahun & $\begin{array}{c}\text { Tarif yang di } \\
\text { tetapkan }\end{array}$ & Subsidi & $\begin{array}{c}\text { Tarif setelah } \\
\text { disubsidi }\end{array}$ \\
\hline 2009 & Rp.6000 & Rp.3000 & $\begin{array}{c}\text { Rp.3000 } \\
\text { (semua } \\
\text { kalangan } \\
\text { masyarakat) }\end{array}$ \\
\hline 2014 & Rp.6.500 & $\begin{array}{c}\text { Rp.2.500 } \\
\text { (masyarakat } \\
\text { umum) }\end{array}$ & $\begin{array}{c}\text { Rp.4000 } \\
\text { (masyarakat } \\
\text { umum) }\end{array}$ \\
\cline { 3 - 4 } & & $\begin{array}{c}\text { Rp.3.500 } \\
\text { (mahasiswa) }\end{array}$ & $\begin{array}{c}\text { Rp.3000 } \\
\text { (mahasiswa) }\end{array}$ \\
\cline { 3 - 4 } & & $\begin{array}{c}\text { Rp.4000 } \\
\text { (Pelajar) }\end{array}$ & $\begin{array}{c}\text { Rp.2.500 } \\
\text { (Pelajar) }\end{array}$ \\
\hline
\end{tabular}

Sumber: Dinas Perhubungan dan Kominfo Kota Pekanbaru 2014
Kurang efisiennya Trans Metro Pekanbaru dari beberapa hal: Pertama, Trans Metro Pekanbaru tidak mempunyai jalur khusus (separator). Kedua, shelter bus ada yang terdapat dimedian jalan sehingga dapat menyebabkan kemacetan. Ketiga, Kecepatan bus Trans Metro Pekanbaru idealnya maksimal 30 kilometer per/jam atau setidaknya rata-rata 25 kilometer per/ jam, namun karena kepadatan kendaraan juga menjadi pemicu kecepatan bus yang rata rata hanya bisa menempuh jarak 18 kilometer per/jam, sehingga membuat waktu tunggu datangnya armada bus Trans Metro Pekanbaru ke setiap shelter yang seharusnya sekitar 10 menit, dapat menjadi lebih dari 10 menit.

Keempat, jadwal waktu kedatangan dan keberangkatan bus Trans Metro yang tidak menentu sehingga menyebabkan enggannya masyarakat memilih transportasi ini. Padahal di dalam prinsip penyelenggaraan transportasi umum pada dasarnya harus menjamin rasa aman, nyaman, mudah, ekonomis, lancar (tepat waktu), ramah lingkungan (Sadyohutomo,2009). Kelima, fasilitas di dalam sebagian Trans Metro Pekanbaru seperti AC beberapa tidak berfungsi dengan sempurna dan banyak yang bocor sehingga banyak penumpang atau konsumen yang terganggu terkena tetesan air, serta pegangan untuk yang berdiri beberapa ada yang lepas. Keenam, shelter ada yang tidak diberikan tempat duduk dan atap untuk calon penumpang menunggu Trans Metro Pekanbaru.

\section{Standar Pelayanan Publik}

Peraturan Menteri Pendayagunaan Aparatur Negara No 20 Tahun 2006 tentang Penyusunan Standar Pelayanan Publik mengemukakan bahwa Standar Pelayanan publik adalah suatu tolak ukur yang dipergunakan sebagai pedoman penyelenggaraan pelayanan dan acuan 
penilaian kualitas pelayanan sebagai komitmen atau janji dari penyelenggara pelayanan kepada masyarakat untuk memberikan pelayanan yang berkualitas. Standar pelayanan memiliki arti yang sangat penting dalam pelayanan publik. Standar pelayanan merupakan suatu komitmen penyelenggara pelayanan untuk menyediakan pelayanan dengan suatu kualitas tertentu yang ditentukan atas dasar perpaduan harapanharapan masyarakat dan kemampuan penyelenggara pelayanan. Penetapan standar pelayanan yang dilakukan melalui proses identifikasi jenis pelayanan, identifikasi pelanggan, identifikasi harapan pelanggan, perumusan visi dan misi pelayanan, analisis proses dan prosedur, sarana dan prasarana, waktu dan biaya pelayanan.

Proses ini tidak hanya akan memberikan informasi mengenai standar pelayanan yang harus ditetapkan, tetapi juga informasi mengenai standar pelayanan yang harus ditetapkan, tetapi juga informasi mengenai kelembagaan yang mampu mendukung terselenggaranya proses manajemen yang menghasilkan pelayanan sesuai dengan standar yang telah ditetapkan. Informasi lain yang juga dihasilkan adalah informasi mengenai kuantitas dan kompetensi-kompetensi sumber daya manusia yang dibutuhkan serta distribusinya beban tugas pelayanan yang akan ditanganinya.

\section{Standar Pelayanan Minimal Angkutan Umum}

Undang-Undang Nomor 22 Tahun 2009 tentang Lalu Lintas dan Angkutan Jalan telah mengatur mengenai Standar Pelayanan Angkutan Orang (Pasal 141) yang mewajibkan Perusahaan yang Angkutan Umum untuk memenuhi standar pelayanan minimal meliputi: keamanan, keselamatan, kenyamanan, keterjangkauan, kesetaraan dan keteraturan. Untuk melaksanakan ketentuan tersebut, Menteri Perhubungan mengeluarkan Peraturan Menteri Perhubungan Nomor 10 Tahun 2012 Tentang Standar Pelayanan Minimal Angkutan Massal Berbasis Jalan:

1. Standar Pelayanan Minimal Angkutan Massal Berbasis Jalan adalah persyaratan penyelenggaraan Angkutan Massal Berbasis Jalan mengenai jenis dan mutu pelayanan yang berhak diperoleh setiap Pengguna Jasa Angkutan Massal Berbasis Jalan secara minimal.

2. Angkutan Massal Berbasis Jalan adalah suatu sistem angkutan umum yang menggunakan mobil bus dengan jalur khusus yang terproteksi sehingga memungkinkan peningkatan kapasitas angkut yang bersifat missal yang dioperasikan di Kawasan Perkotaan.

3. Kawasan Perkotaan adalah adalah wilayah yang mempunyai kegiatan utama bukan pertanian dengan susunan fungsi kawasan sebagai tempat permukiman perkotaan, pemusatan dan distribusi pelayanan jasa pemerintahan, pelayanan sosial dan kegiatan ekonomi.

4. Kawasan Megapolitan adalah kawasan yang terbentuk dari 2 (dua) atau lebih Kawasan Metropolitan yang memiliki hubungan fungsional dan membentuk sebuah sistem.

5. Kawasan Metropolitan adalah Kawasan Perkotaan yang terdiri atas sebuah Kawasan Perkotaan yang berdiri sendiri atau Kawasan Perkotaan inti dengan Kawasan Perkotaan di sekitarnya yang saling memiliki keterkaitan fungsional yang dihubungkan dengan sistem jaringan prasarana wilayah yang terintegrasi dengan jumlah penduduk secara keseluruhan sekurang-kurangnya 1.000.000 jiwa.

6. Kawasan Perkotaan Besar adalah Kawasan Perkotaan yang terdiri atas sebuah Kawasan Perkotaan yang berdiri sendiri atau Kawasan Perkotaan inti 
dengan Kawasan Perkotaan di sekitarnya yang saling memiliki keterkaitan fungsional yang dihubungkan dengan sistem jaringan prasarana wilayah yang terintegrasi dengan jumlah penduduk antara 500.000 sampai dengan 1.000.000 jiwa.

7. Kawasan Aglomerasi Perkotaan adalah Kawasan Perkotaan yang terdiri atas sebuah Kawasan Perkotaan yang terdiri sendiri atau Kawasan Perkotaan inti dengan Kawasan Perkotaan di sekitarnya yang saling memiliki keterkaitan fungsional yang dihubungkan dengan sistem jaringan prasarana wilayah yang terintegrasi dan membentuk sebuah sistem.

\section{Layanan Transportasi}

Layanan transportasi adalah memindahkan barang atau manusia dari satu tempat ke tempat lain sehingga diperoleh manfaat. Manfaat perpindahan tersebut dapat dilihat dari berbagai aspek sesuai tujuannya, yaitu aspek ekonomi, sosial, politis, bahkan hankam. Penyelenggaraan layanan transportasi berdasarkan pada prinsip-prinsip berikut:

1. Aman; barang yang dipindah tidak menjadi rusak atau cacat. Kalau untuk manusia, prinsip aman mencakup bebas dari cidera atau sampai merenggut jiwa.

2. Nyaman; barang mati tidak mengalami penurunan kualitas, barang hidup (hewan, tumbuhan) tidak tersiksa dan mengalami penurunan kualitas. Sedangkan manusia perlu merasa nyaman sejak persiapan, selama perjalanan, maupun sesudah menempuh perjalanan.

3. Mudah; tingkat kemudahannya diukur dengan seberapa banyak pilihan yang tersedia bagi konsumen, seperti jenis kendaraan, rute perjalanan, jadwal waktu pelayanan dan biaya. Semakin banyak pilihan yang tersedia menunjukkan tingkat kemudahan dan fleksibilitas perjalanan bagi masyarakat.

4. Ekonomis; murah, terjangkau semua lapisan masyarakat.

5. Lancar; menjamin ketepatan waktu dalam penyediaannya dan waktu tempuh yang sesingkat-singkatnya.

6. Ramah Lingkungan; tidak berdampak negative (misalnya getaran, kebisingan dan gas buang) yang dapat merusak lingkungan.

\section{Trans Metro Pekanbaru}

Penduduk Kota Pekanbaru saat ini lebih kurang berjumlah 850.000 jiwa (BPS Kota Pekanbaru tahun 2010) setiap tahunnya akan bertambah. Semakin bertambah jumlah penduduk semakin banyak pula permasalahan yang ada terutama masalah transportasi di perkotaan. Saat ini jumlah kendaraan pribadi di kota Pekanbaru tidak sebanding dengan jumlah ruas jalan yang ada sehingga menyebabkan kemacetan, pemborosan penggunaan bahan bakar, kebisingan serta tingginya tingkat polusi dan pemandangan yang tidak enak karena lalu lintas yang sembrawut. Untuk menyikapi masalah tersebut Pemerintah Kota Pekanbaru mengeluarkan kebijakan pelayanan transportasi perkotaan yang biasanya dikenal dengan "SAUM" yang merupakan singkatan dari Sistem Angkutan Umum Massal. Bus yang digunakan bernama Bus Trans Metro Pekanbaru. Sistem angkutan ini dilaksanakan berdasarkan surat Keputusan Menteri Perhubungan Nomor 111 tahun 2009.

Trans Metro Pekanbaru ini mulai beroperasi pada tanggal 18 Juni 2009. Pertumbuhan penumpangnya cukup bagus. Trans Metro Pekanbaru merupakan transportasi yang didambakan oleh masyarakat Pekanbaru karena selain bisa memberikan pelayanan, aman, nyaman dan juga terjangkau oleh masyarakat angkutan umum. Trans Metro Pekanbaru adalah sistem 
angkutan umum masal di kota Pekanbaru, merupakan solusi untuk mengatasi kemacetan secara bertahap dan terprogram bagi masyarakat. Pada awal operasional Bus Trans Metro Pekanbaru mendapat bantuan dari Kementerian Perhubungan berjumlah 20 unit untuk 2 koridor pertama. Sejak bulan Juni 2013 operasional bus Trans Metro Pekanbaru telah ditambah sebanyak 50 unit, untuk 5 koridor baru. Jadi total bus Trans Metro Pekanbaru sekarang sebanyak 70 unit untuk 7 koridor dengan 182 shelter yang tersebar di wilayah kota Pekanbaru. Keberadaan Trans Metro Pekanbaru di Pekanbaru tidak terlepas dari campur tangan pemerintah pusat yang mengemukakan konsep Sistem Angkutan Umum Massal dan memberikan bantuan dalam proyek ini. Regulasi pemerintah yang mengatur penyerahan kewenangan Pemerintah Kota Pekanbaru dalam pengoperasian armada angkutan darat bus Trans Metro Pekanbaru sesuai dengan tupoksi Dinas Perhubungan, Komunikasi dan Informatika berdasarkan Peraturan Daerah Kota Pekanbaru No 08 Tahun 2008 dan MOU antara Pemerintah Kota dan Pemerintah Pusat dalam hal ini Departemen Perhubungan dalam rangka pengembangan Sistem Angkutan Umum Massal Nomor : AJ.206/2/6/DRJD/2007 dan 06/WK/III/2007 tanggal 09 Maret 2007. Kebijakan Pemerintah dalam pengaturan kewenangan angkutan adalah dalam rangka mereformasi sistem angkutan umum dalam memberikan pelayanan kepada masyarakat tanpa meninggalkan para pelaku usaha sektor angkutan darat yang telah ada.

Trans Metro sejak dioperasikan hingga sekarang telah melayani sembilan koridor, yakni :

1. Koridor satu; Pelita Pantai - Pandau, yang menghubungkan Pelita Pantai - Jl. Jend. Sudirman - Bandar Udara SSQ II Jl. Kaharuddin Nasution - Jl. Pasir Putih - Perumnas Pandau.
2. Koridor dua; Terminal BRPS - Kulim PP, yang menghubungkan Terminal Bandar Raya Payung Sekaki - Jl. T. Tambusai Jl. Jend. Sudirman (U-Turn RRI) - Jl. Jend. Sudirman - Jl. Imam Munandar Kulim Atas.

3. Koridor tiga; Kampus UIN yang menghubungkan Kampus UIN Panam Jl. HR Subrantas - Jl. Arifin Ahmad - Jl. Sudirman (berhenti di Halte Dipo bagi yang ingin transit. Kemudian mutar di bawah Fly Over Harapan Raya dan berhenti di halte Awal Bross untuk transfer).

4. Koridor empat A; yang menghubungkan Pasar Tangor - Jl. Hangtuah - Jl. Sudirman (U Turn RRI) - Jl. Sudirman J1. Samratulangi - Jl. A. Yani - Jl. Riau Jl. Panglima Undan - J1. Senapelan Pasar Wisata (Pasar Bawah) - Jl. A. Yani - Jl. Juanda (U-Turn Telkom).

5. Koridor empat B; yang menghubungkan Terminal Bandar Raya Payung Sekaki (BRPS) - Mall SKA - Jl. Arengka (Soekarno Hatta) - Jl. Riau - Mall Ciputra - Jl. Panglima Undan - Jl. Senapelan - Pasar Wisata (Pasar Bawah) - Jl. A. Yani - Jl. Riau - BPRS.

6. Koridor lima A; yang menghubungkan Sei Duku - Jl. Sutomo - Jl. Beringin - Jl. Pattimura - Jl. Diponegoro - Jl. Hangtuah - Jl. H.M Dahlan - Jl. Sisingamangaraja (U-Turn Korem) - Jl. H.M. Dahlan - Jl. Hangtuah - Jl. Diponegoro.

7. Koridor lima B; yang menghubungkan Sei Duku - J1. Sutomo - Jl. Setia Budi Jl. Sudirman - Jl. Gajah Mada - Jl. Diponegoro (U-Turn Bundaran Jl. Pattimura) - Jl. Gajah Mada - Jl. Sudirman (U-Turn Dibawah Jembatan Siak IV) - Jl. Setia Budi - Tanjung Datuk - Sei Duku.

8. Koridor enam; yang menghubungkan Torganda Pasir Putih - Simpang Marpoyan - Jl. Kaharuddin Nasution - 
Baterai R - Jl. Sukarno Hatta - Pasar Pagi Arengka - J1. Subrantas - J1. SM. Amin Terminal BRPS.

9. Koridor tujuh A; yang menghubungkan Simpang Kaharuddin Nasution (Kartama) - Impres - Jl. Rambutan - Jl. Arifin Ahmad (U-Turn SPBU) - Jl. Arifin Ahmad - Jl. Paus - Jl. T. Tambusai - Jl. Paus (U-Turn Global Bangunan) - Jl. T. Tambusai (U- Turn Simpang Masjid) - Jl. Paus.

10. Koridor delapan A; yang menghubungkan Kantor Walikota - Jl. Cut Nyak Dien - Jl. A. Yani - Ps Bawah - Jl. Riau Jembatan Siak Hulu II - Umban Sari Yos Sudarso - Unilak.

11. Koridor delapan B; yang menghubungkan Unilak - Simpang Bingung - Palas - Jl. Muara Fajar - Kantor Camat Rumbai - Jl. Padat Karya - Jembatan Siak II - Umban Sari - Unilak.

12. Koridor Sembilan; yang menghubungkan Jalur Pekanbaru - Kecamatan Siak Hulu, Kabupaten Kampar.

\section{Pelaksanaan Pelayanan \\ 1. Keamanan}

Keamanan merupakan standar minimal yang harus dipenuhi untuk terbebasnya pengguna jasa dari gangguan perbuatan melawan hukum dan/ atau rasa takut. Fenomena kekerasan di transportasi publik menunjukan bahwa aspek keamanan pada transportasi publik belum dapat perhatian serius dari stakeholder transportasi publik. Keamanan bagi pengguna ruang publik termasuk pengguna jasa angkutan umum masih dianggap hanya sebagai tanggung jawab pribadi. Keamanan dalam transportasi publik menjamin keamanan pengguna jasa untuk menikmati layanan jasa transportasi publik. Keamanan dalam pelayanan transportasi publik ada 2 indikasi yaitu:
1. Keamanan terhadap copet, penipuan, pencurian, hipnotis dan pelecehan seksual di dalam shelter

2. Keamanan terhadap copet dan pelecehan seksual di dalam bus

Diketahui bahwa keamanan di dalam bus Trans Metro Pekanbaru cukup baik, dimana di dalam bus terdapat lampu penerangan yang sesuai dengan Standar Pelayanan Minimal dan juga identitas kendaraan serta tanda pengenal pramudi dan pramugara ditempel didalam bus, guna untuk memudahkan pengguna jasa bila mendapat pelayanan yang kurang baik dari pemberi jasa layanan, sehingga pengguna jasa dapat mengadukan/ melaporkan kepada perusahaan pengelola Trans Metro pekanbaru dengan identitas petugas layanan yang jelas.

Dari uraian hasil pernyataan responden mengenai keamanan Trans Metro Pekanbaru dikatakan cukup baik. Namun keamanan di shelter masih ada yang perlu diperbaiki, dimana ada responden yang menjawab keamanan Trans Metro masih kurang baik dikarenakan tidak adanya petugas keamanan.

Dari kutipan wawancara dengan Kasi Analisis dan Evaluasi PD. Pembangunan Kota Pekanbaru; Bapak Edri Nofrizal, Amd dapat dikatakan bahwa keamanan di Trans Metro Pekanbaru cukup baik, karena pelaksanaan pelayanan keamanan Trans Metro Pekanbaru sudah sesuai dengan Standar Pelayanan Minimal. Hanya saja untuk mengadakan petugas keamanan di shelter atau di bus tidak dapat dilakukan karena terkendala oleh dana yang tidak cukup. Namun dari pengamatan penulis di Trans Metro Pekanbaru dimana pelaksaan dari standar pelayanan minimal yang indikator keamanan masih kurang dimana di shelter tidak diberikan informasi gangguan keamanan dan di dalam bus semua tanda pengenal pramudi dan pramugara terpasang. 


\section{Keselamatan}

Keselamatan merupakan standar minimal yang harus dipenuhi untuk terhindarnya dari risiko kecelakaan disebabkan oleh faktor manusia, sarana dan prasarana. Dimana banyak terjadinya kecelakaan lalu lintas di sekitar kita. Kecelakaan lalu-lintas adalah kejadian dimana sebuah kendaraan bermotor tabrakan dengan benda lain dan menyebabkan kerusakan. Kadang kecelakaan ini dapat mengakibatkan luka-luka atau menelan korban jiwa manusia atau hewan. Dari kejadian yang dijelaskan di atas menunjukkan bawah pemerintah dan pelaku industri transportasi publik belum mampu menjamin keselamatan pengguna jasa angkutan umum.

Keselamatan merupakan prioritas utama dalam pengembangan sistem tranportasi publik sehingga perlu ditangani dengan sebaik-baiknya sehingga dapat menanggulangi penurunan angka kecelakaan lalu-lintas. Keselamatan dalam pelayanan transportasi publik ada 3 indikasi yaitu:

1. Keselamatan di dalam shelter

2. Keselamatan di dalam bus

3. Keselamatan di sepanjang koridor

Keselamatan manusia dalam Standar Operasional Prosedur (SOP) cukup baik dalam pengoperasian kendaraan Trans Metro Pekanbaru dan penanganan keadaan darurat, diketahui bahwa keselamatan manusia dalam standar operasional prosedur cukup baik dimana tata tertib pengoperasian kendaraan yang wajib ditaati oleh pramudi telah dijalankan dengan cukup baik serta tata tertib untuk menaikkan dan menurunkan pengguna jasa dilakukan di tempat yang telah ditentukan yakni di shelter yang telah di sediakan disepanjang koridor Trans Metro Pekanbaru. Namun ada juga diantara pramudi Trans Metro Pekanbaru yang mengemudi bus Trans Metro Pekanbaru kurang hati-hati dimana terjadi kecelakaan lalu-lintas dan memakan korban. Serta ada satu dan dua bus Trans Metro Pekanbaru yang pramudi atau pramugara menaikkan dan menurunkan pengguna jasa di tempat selain shelter Trans Metro Pekanbaru.

Dari kutipan wawancara dengan Kasi Analisis dan Evaluasi PD. Pembangunan Kota Pekanbaru; Bapak Edri Nofrizal, Amd dapat dikatakan jaminan keselamatan untuk pengguna jasa Trans Metro Pekanbaru sudah cukup baik, karena adanya jaminan keselamatan atau asuransi yang disediakan oleh pengelola untuk pengguna jasa selama menggunakan bus TMP.

Kemudian keselamatan di bus Trans Metro Pekanbaru cukup baik karena di dalam bus terdapat alat untuk penyelamatan saat darurat seperti palu pemecah kaca, tabung pemadam kebakaran dan tombol pembuka pintu otomasi yang dipasang di tempat yang mudah dicapai serta dilengkapi dengan keterangan tata cara penggunaan yang berbentuk stiker. Serta stiker informasi tanggap darurat yang berisi nomor telepon ataupun layanan sms pengaduan yang ditempel di dalam bus pada tempat yang strategis dan mudah terlihat.

\section{Kenyamanan}

Kenyamanan merupakan standar minimal yang harus dipenuhi untuk memberikan suatu kondisi nyaman, bersih, indah dan sejuk yang dapat dinikmati pengguna jasa. Pengguna jasa publik juga belum dapat menikmati kenyamanan. Dari hasil observasi dan pemberitaan di berbagai media massa menunjukkan angkutan umum seringkali diisi penumpang melebihi kapasitas kendaraan, sehingga penumpang harus berdesak-desakan dan tidak ada kepastian memperoleh tempat duduk meskipun membayar dengan tarif penuh. Pengemudi angkutan umum tidak jarang berkebut-kebutan tanpa memperhatikan kenyamanan pengguna jasa. Kenyamanan 
pada transportsi publik menjamin bahwa jasa layanan transportasi publik akan dapat dinikmati oleh pelanggan jasa secara nyaman. Pelayanan kenyamanan pada transportasi publik ada 10 indikasi yaitu:

1. Kebersihan di dalam shelter

2. Suhu di dalam shelter

3. Penerangan di dalam shelter

4. Kepadatan penumpang di dalam shelter

5. Kebersihan di dalam bus

6. Suhu di dalam bus

7. Penerangan di dalam bus

8. Kepadatan penumpang di dalam bus

9. Waktu tunggu

10. Pelayanan petugas

Diketahui bahwa kenyamanan di shelter Trans Metro Pekanbaru kurang baik, karena pengguna jasa layanan melihat didalam shelter Trans Metro Pekanbaru tidak diberikan lampu penerangan dimalam hari untuk pengguna jasa layanan, di dalam shelter juga tidak disediakan tempat sampah yang membuat sampah di shelter berserakan serta bau pesing yang menyengat. Tangga di beberapa shelter letaknya terlalu tinggi untuk pengguna jasa yang hendak naik/ turun dari bus, khusus bagi wanita yang memakai rok harus mengangkat roknya agar dapat menaikki tangga dari dalam bus dan sebaliknya melompat dari tangga untuk masuk ke dalam bus.

Dilanjutkan kutipan wawancara dapat dikatakan kenyamanan di Trans Metro Pekanbaru kurang baik karena pengelola Trans Metro Pekanbaru tidak sepenuhnya dapat memberikan pelayanan yang maksimal kepada pengguna jasa khususnya di sheltershelte Trans Metro Pekanbaru yang disebabkan Pengelola Trans Metro Pekanbaru hanya berhak memberikan pelayanan di bus saja dan pengelola hanya sebagai operator bus Trans Metro Pekanbaru saja. Sehingga pihak pengelola Trans Metro Kota Pekanbaru tidak dapat melakukan perbaiki fasilitas di shelter Trans Metro Pekanbaru karena mereka tidak bertanggung jawab atas pengelolaan shelter Trans Metro Pekanbaru.

Dari data diatas diketahui bahwa lebih banyak yang menjawab kenyamanan di dalam bus Trans Metro Pekanbaru cukup baik karena di dalam bus Trans Metro Pekanbaru tersedia tempat sampah dan sapu sehingga didalam lantainya terlihat bersih dari sampah, serta dimalam hari lampu penerangan di dalam bus menyala dengan baik. Adapun kelemahan masih terdapat beberapa alat pengatur suhu/ Air Conditioner (AC) yang tidak berjalan dengan baik, dimana ada tetesan air yang berasal dari AC bus yang kadang mengenai pengguna jasa yang sedang duduk maupun berdiri.

\section{Keterjangkauan}

Keterjangkauan merupakan standar minimal yang harus dipenuhi untuk memberikan kemudahan bagi pengguna jasa mendapatkan akses Angkutan Massal Berbasis Jalan dan dengan tarif terjangkau. Pertumbuhan kawasan perumahan yang terus meningkat dan tidak seimbangnya dengan ketersediaan sarana transportasi publik. Belum terintegrasinya moda angkutan umum serta tingginya tarif angkutan umum membatasi keterjangkauan transportasi publik bagi masyarakat, terutama masyarakat yang berketerbatasan ekonomi. Kondisi ini menjadi kendala dalam mobilitas masyarakat, terutama masyarakat yang tinggal di kawasan perumahan baru yang umumnya terletak jauh dari pusat kegiatan ekonomi, sosial, budaya, politik, layanan publik, dsb. Setiowarno, (11 juni 2013).

Dari keterjangkauan transportasi publik memberikan kemudahan kepada pengguna jasa untuk dapat menikmati berbagai jasa layanan transportasi publik. Kemudahan pada pelayanan transportasi publik ada 4 indikasi yaitu: 
1. Kemudahan mendapatkan informasi tentang transportasi publik

2. Kemudahan melaporkan kehilangan/ menemukan barang

3. Kemudahan menyampaikan pengaduaan, memberikan saran.

4. Kemudahan akses menuju/ dari shelter

\section{Kesetaraan}

Kesetaraan merupakan standar minimal yang harus dipenuhi untuk memberikan perlakuan khusus berupa aksesibilitas, prioritas pelayanan dan fasilitas pelayanan bagi pengguna jasa penyandang cacat, manusia usia lanjut (manula), anak-anak dan ibu hamil. Transportasi publik di Indonesia juga belum memperhatikan aspek kesetaraan dalam layanannya. Dimana sarana dan prasarana transportasi publik yang ada belum dapat mengakomodasi kebutuhan spesifik kelompok sosial termaginal seperti penyandang cacat, manusia usia lanjut (manula), anak-anak, ibu hamil dan orang sakit.

Dapat diketahui bahwa kursi prioritas yang ada sudah cukup baik, karena di dalam bus Trans Metro Pekanbaru disediakan tempat duduk atau kursi prioritas khusus diperuntukkan bagi penyandang cacat, manusia lanjut usia (manula), anak-anak dan ibu hamil dengan keadaan kursi yang baik. Adapun yang menjadi masalah pada kenyataannya kursi prioritas tersebut belum dapat difungsikan seharusnya dimana penulis melihat kursi perioritas tersebut digunakan untuk pengguna yang luar dari kategori yang berhak menggunakan kursi prioritas tersebut.

\section{Keteraturan}

Keteraturan merupakan standar minimal yang harus dipenuhi untuk memberikan kepastian waktu pemberangkatan dan kedatangan mobil bus serta tersedianya fasilitas informasi perjalanan bagi pengguna jasa. Masalah lain yang dihadapi pengguna jasa transportasi publik adalah belum adanya keteraturan. Permasalahan ini terlihat dari pola rute angkutan umum yang belum sesuai kebutuhan pengguna jasa sehingga harus terjadi transfer beberapa kali; tidak adanya jadwal keberangkatan yang tetap; headway yang tidak teratur; dari waktu sampai ke tempat tujuan yang tidak dapat dipastikan. Sebagai akibatnya pengguna jasa angkutan umum terpaksa harus mengalokasikan waktu lebih banyak untuk perjalanan, serta mengalami penurunan kualitas kerja dan kualitas kesehatan akibat kelelahan di perjalanan, dan kehilangan waktu untuk interaksi sosial dengan keluarga dan lingkungan, Hendratno (2009). Keteraturan atau kehandalan pelayanan menjamin kehandalan operasional, termasuk kesiapan operasional bus, sarana dan prasarana, sistem operasi dan petugas operasi.

Dapat diketahui bahwa pengguna jasa untuk menunggu kedatangan bus lebih dari 15 menit, tak jarang pengguna harus menunggu selama 20 menit, sehingga pengguna jasa harus mengatur ulang jadwal keberangkatan mereka ketika menggunakan bus Trans Metro Pekanbaru agar tidak terlambat sampai ditujuan.

Dari kutipan wawancara diatas dapat dikatakan bahwa waktu tunggu bus Trans Metro Pekanbaru sudah diatur dengan baik oleh pihak pengelola, namun dilapangan tidak dapat di aplikasikan dengan baik, karena berbagai kendala yang terjadi dilapangan. Selama penulis menyebarkan angket di shelter Trans Metro Pekanbaru, penulis melihat calon pengguna jasa menunggu kedatangan bus Trans Metro Pekanbaru lebih dari 10 menit, dan kadang membuat calon penumpang kesal dengan kedatangan bus yang lama.

\section{Kesimpulan dan Saran}

\section{Kesimpulan}


a. Keamanan merupakan standar minimal yang harus dipenuhi Trans Metro Pekanbaru untuk terbebasnya Pengguna Jasa dari gangguan perbuatan melawan hukum dan/ atau rasa takut. Dan juga transportasi publik menjamin keamanan pelanggan saat menikmati layanan jasa transportasi publik

b. Keselamatan merupakan standar minimal yang harus dipenuhi untuk terhindarnya dari resiko kecelakaan disebabkan oleh faktor manusia, sarana dan prasarana. keselamatan merupakan perioritas utama dalam pengembangan sistem transportasi sehingga perlu ditangani dengan sebaikbaiknya sehingga setiap program yang dibuat oleh pemerintah merupakan bagian dari penurunan angka kecelakaan lalu lintas.

c. Kenyamanan merupakan standar minimal yang harus dipenuhi untuk memberikan suatu kondisi nyaman, bersih, indah dan sejuk yang dapat dinikmati Pengguna Jasa. Transportasi publik menjamin bahwa jasa layanan transportasi publik akan dinikmati pelanggan secara nyaman.

d. Keterjangkauan merupakan standar minimal yang harus dipenuhi untuk memberikan kemudahan bagi Pengguna Jasa mendapatkan akses Angkutan Massal Berbasis Jalan dan tarif yang terjangkau.

e. Kesetaraan. Merupakan standar minimal yang harus dipenuhi untuk memberikan perlakuan khusus berupa aksesibilitas, prioritas pelayanan dan fasilitas pelayanan bagi PenggunaJasa penyandang cacat, manusia usia lanjut, anak-anak, dan wanita hamil.

f. Keteraturan. Merupakan standar minimal yang harus dipenuhi untuk memberikan kepastian waktu pemberangkatan dan kedatangan mobil bus serta tersedianya fasilitas informasi perjalanan bagi Pengguna Jasa

\section{Saran}

Adapun saran penulis mengenai pelaksanaan pelayanan transportasi pada angkutan Trans Metro Kota Pekanbaru adalah sebagai berikut :

1. Agar Pemerintah Daerah dapat menetapkan Standar Pelayanan Minimal sesegera mungkin sehingga dapat memenuhi visi Trans Metro Pekanbaru yaitu "menjadikan Trans Metro Pekanbaru sebagai solusi transportasi perkotaan yang aman, nyaman, andal, terjangkau dan ramah lingkungan. Standar pelayanan minimal tidak perlu disempurnakan pada tahap awalnya dan secara bertahap dilakukan penyempurnaan-penyempurnaan sehingga dapat memenuhi standar kelas dunia.

2. Dalam pelaksanaan Trans Metro Pekanbaru agar mengacu pada Standar Pelayanan Minimal Angkutan Massal Berbasis Jalan. Melalui pedoman tersebut, diharapkan Trans Metro Pekanbaru akan menjadi alternative transportasi yang terjangkau dengan kualitas pelayanan yang memuaskan.

3. Trans Metro Pekanbaru harus meningkatkan pelayanan yang baik kepada pengguna jasa, mengingat sistem sekarang bukanlah sistem setoran melainkan sistem pembelian pelayanan. Sehingga bila ada kepuasan terhadap pengguna jasa, maka akan semakin meningkat jumlah pengguna jasa Trans Metro Pekanbaru dan membuat Trans Metro Pekanbaru menjadi Transportasi pilihan yang baik bagi masyarakat Pekanbaru.

\section{DAFTAR PUSTAKA}

Undang-Undang Nomor 22 Tahun 2009 tentang Lalu Lintas dan Angkutan Jalan telah 
Peraturan Menteri Pendayagunaan Aparatur Negara No 20 Tahun 2006 tentang Penyusunan Standar Pelayanan Publik

Peraturan Menteri Perhubungan mengeluarkan Peraturan Menteri Perhubungan Nomor 10 Tahun 2012 Tentang Standar Pelayanan Minimal Angkutan Massal Berbasis Jalan

Keputusan Menteri Perhubungan Nomor 111 tahun 2009 Tentang Penetapan Kota Pekanbaru Propinsi Riau Sebagai Kota Percontohan Di Bidang Transportasi Perkotaan 